\title{
Reversal of Paracetamol Induced Hepatotoxicity in Animals Model: Clove, an Alternative Medicine beyond the Spices
}

\author{
Sadia Kazi, Mashkoor Ahmed Ansari, Ashfaque Rahim Memon, \\ Abdul Rahim Memon, Qamar Zaman Phull
}

\section{ABSTRACT}

INTRODUCTION: Clove is used as spice commonly and exerts beneficial effects in different human pathologies especially diabetes and infectious diseases discovered in recent times.

OBJECTIVE: Current study was aimed to investigate the effects of clove extract on paracetamol induced liver toxicity.

METHODOLOGY: This animal study was conducted in Department of pharmacology, Isra University Laboratory Hyderabad and at animal house of veterinary department, Sindh Agriculture University, Tando Jam between September 2013 to October 2013. Through non probability purposive sampling, 30 Rabbits were divided into three groups I, II and III. Acetaminophen $500 \mathrm{mg}$ was given to group II and III for 10 days orally, while group I served as control. Group III was co administered $100 \mathrm{mg}$ of clove powder for 20 days while group II was started $100 \mathrm{mg}$ clove powder on $11^{\text {th }}$ day till $20^{\text {th }}$ day of experiment. All blood samples were taken from ear lobe Base line blood sample before intervention was taken at day 0 , then $2^{\text {nd }}$ and $3^{\text {rd }}$ samples were taken at 10 and 20 days respectively after intervention. Liver enzymes were also measured. Data was analyzed on SPSS version 21 using t-test, keeping P-value $<0.05$ significant.

RESULTS: No significant rise in liver enzymes noticed in group I and group III while all enzymes were increased in group II in initial 10 days but declined back in next 10 days. P-value calculated was $\mathbf{0 0 2}$, 0.001 and 0.001 for ALT,AST and GGT respectively.

CONCLUSION: Paracetamol induced elevation of hepatic enzymes was reversed by clove.

KEYWORDS: Clove, Alanine Transferase (ALT), Aspartate Transaminase(AST), Gama Glutamyl Transferase (GGT)

This article may be cited as: Kazi S, Ansari MA, Memon AR, Memon AR, Phull QZ. Reversal of Paracetamol Induced Hepatotoxicity in Animal Model: Clove, an Alternative Medicine beyond the Spices. J Liaquat Uni Med Health Sci. 2017;16(03):154-7.

doi: 10.22442/jlumhs.171630525

\section{INTRODUCTION}

Plant leaves, roots, seeds and herbs had been used as medicine for long times. Many of the allopathic drugs have been derived from the plants like atropine an anticholinergic agent from belladona tree, digoxin a cardiac glycoside from fox glove plants. Similarly, quinine and morphine also belong to plant sources. Alternative medicine has been now recognized all over the world. Licenses are being issued in USA, Japan, China, Korea, Turkey and Middle East to practice alternative medicine. Clove belongs to Mirtaceae family and its botanical name is Eugenia Caryophyllata. Clove has attracted the researchers mainly due to its potent antioxidant and antimicrobial activities differentiating it from other spices ${ }^{1}$. Clove was used in ancient China as a spice and fragrance for 2,000 years. The well-known traditional remedy to treat a toothache with clove oil was documented first time in France in 1640. Chinese also used clove oil as carminative, antispasmodic, antibacterial and antiparasitic agent and the clove buds to treat dyspepsia, acute/chronic gastritis and diarrhea ${ }^{2}$. Phenolic compound, eugenol is reported to be the major chemical constituent present in the clove oil, which may be responsible for its biological activities.

The oil also contains eugenol acetate, $\beta$-caryophyllene, chavicol, humulenes in lesser amounts $^{3,4}$. As a result of its broad range of pharmacological and biological activities, studies on eugenol and others clove ingredients are currently a research priority ${ }^{2,4}$. Liver is the main organ of the body where metabolism of most of the drugs takes place. Any alteration in the liver function immediately affects the health status resulting in marked fatigue, anorexia followed by nausea, vomiting along with jaundice and elevated liver enzymes. Markers of the Liver injury are 
ALT, AST and GGT for showing any disturbance in the liver as well as any improvement in the liver functions after injury. Large number of factors affects the liver functions which include infections such as bacteria, viruses, worms, protozoa and drugs like acetaminophen and isoniazide. Acetaminophen is very commonly used for effective pain relief and fever suppression. It retains its safety profile at therapeutic doses but when its therapeutic index is breached, it may cause acute orchronic hepato-renal damage in human as well as experimental animals ${ }^{5}$. Normally acetaminophen is metabolized through sulfation and glucuronidation (95\%) while $5 \%$ is metabolized by an alternate pathway depending upon cytochrome p450 and Glutathions. When higher doses of acetaminophen are taken the normal metabolism gets saturated but hepatotoxicity does not occur till hepatic GHS (Glutathione) are present for conjugation. When the rate of hepatic GHS depletion exceeds the synthesis as a result the reactive, toxic metabolite accumulates ( $\mathrm{N}$-acetylbenzoiminoquinone). In the absence of intracellular GHS, this reactive metabolite reacts with nucleophilic groups of cellular proteins, resulting in hepatotoxicity ${ }^{6}$.

Current research was performed to evaluate the effects of the clove on the liver enzymes which were raised by high dose of acetaminophen.

\section{METHODOLOGY}

The project was funded by Isra University, Hyderabad, Sindh and approved by ethical review committee. Mature male rabbits were purchased from Karachi. Prior to experimental procedure, to get acclimatized these were kept for 2 weeks in the animal house of veterinary department Sindh Agriculture University Tando Jam. Data collected was analyzed on student's t-test, after collecting reports from the Isra laboratory. Experimental protocol was adapted as previously published guidelines earlier. $^{7}$

\section{Clove powder preparation}

Clove was purchased from local market of Hyderabad city identified by seed experts for being original and fresh. Clove buds were grinded and crushed by using mortar and pestle in post graduate laboratory of Isra University. Powder was measured by fine vacuumed weighing scale up to $100 \mathrm{mg}$ each and filled in empty capsules for use in animal feeding.

\section{Animal Grouping and drug administration}

Three groups were set as I, II, III with 10 rabbits in each Group-I served as control group. Paracetamol and clove powder was administered orally dissolved in water after opening the capsules according to measured weight of the animals and calculated dosage.

\section{Enzyme analysis}

Serum obtained after centrifugation of the whole blood was analyzed in Hitachi analyzer for estimation of liver enzymes.

\section{Data Analysis Plan}

Data collected from the laboratory was analyzed on SPSS 21 version and t-test was used as statistical technique. Mean and standard deviation of enzymes levels in each group was compared at different levels of the study.

\section{RESULTS}

Experimental animals from group I and III did not show any significant elevation in liver enzymes with p-values $0.81,0.68,0.67$ and $0.91,0.89,0.87$ for ALT, AST and GGT respectively. Animals from group II showed elevation of all enzymes in initial 10 days as clove powder was not given but all enzymes levels declined back in next 10 days once clove administration started. With a highly significant P-Value 0.002, 0.001 and 0.001 for ALT,AST and GGT respectively.

TABLE 1: SHOWING CHANGES IN ALANINE TRANSAMINASES LEVELS DURING STUDY

\begin{tabular}{|l|c|c|c|c|r|}
\hline Enzyme & Group & Day 01 & Day 10 & Day 20 & $\begin{array}{c}\text { P- } \\
\text { Value }\end{array}$ \\
\hline $\begin{array}{l}\text { Alanine } \\
\text { Transa- } \\
\text { minase }\end{array}$ & $\mathrm{I}$ & $38.49 \pm 13.50$ & $37.62 \pm 12.29$ & $37.55 \pm 11.90$ & 0.81 \\
\cline { 2 - 6 } & $\mathrm{II}$ & $31.49 \pm 12.30$ & $81.72 \pm 12.15$ & $39.63 \pm 12.58$ & 0.002 \\
\cline { 2 - 6 } & $\mathrm{III}$ & $39.39 \pm 11.22$ & $42.32 \pm 11.58$ & $40.25 \pm 11.46$ & 0.91 \\
\hline
\end{tabular}

TABLE II: SHOWING CHANGES IN ASPARTATE TRANSAMINASES LEVELS DURING STUDY PERIOD

\begin{tabular}{|l|c|c|c|c|r|}
\hline Enzyme & Group & Day 01 & Day 10 & Day 20 & $\begin{array}{c}\text { P- } \\
\text { Value }\end{array}$ \\
\hline \multirow{2}{*}{$\begin{array}{l}\text { Aspartate } \\
\begin{array}{l}\text { Transa- } \\
\text { minase }\end{array}\end{array}$} & I & $33.79 \pm 5.81$ & $33.02 \pm 4.52$ & $32.45 \pm 4.85$ & 0.68 \\
\cline { 2 - 6 } & III & $25.89 \pm 10.29$ & $67.42 \pm 14.80$ & $35.03 \pm 11.34$ & 0.001 \\
\hline
\end{tabular}

TABLE III: SHOWING CHANGES IN GAMA GT LEVELS DURING STUDY PERIOD

\begin{tabular}{|l|c|c|c|c|r|}
\hline Enzyme & Group & Day 01 & Day 10 & Day 20 & $\begin{array}{c}\text { P- } \\
\text { Value }\end{array}$ \\
\hline $\begin{array}{l}\text { Gamma } \\
\text { Glutamyl } \\
\begin{array}{l}\text { Trans- } \\
\text { ferases }\end{array}\end{array}$ & I & $30.05 \pm 13.29$ & $30.43 \pm 13.01$ & $31.00 \pm 12.20$ & 0.67 \\
\cline { 2 - 6 } & III & $36.21 \pm 9.35$ & $83.23 \pm 12.62$ & $45.13 \pm 10.80$ & 0.001 \\
\hline
\end{tabular}




\section{DISCUSSION}

In the current study Clove reversed the elevated liver enzymes induced by paracetamol as demonstrated in tables I,II,III. Although we used clove as a whole, however it is believed that eugenol component of clove is responsible for that as it possess the antioxidant properties ${ }^{1,7,12}$. Different herbs have been used in animal models to reverse the paracetamol induced hepatotoxicity. Abdel-Rahman. MK et al found the improvement in histology of hepatic cells after administration of clove and other herbal drugs on Mice model ${ }^{8}$, he used histological procedure while current study was a rabbit model limited to serum enzymes only. Other work of this nature could not be found on search however many others have studied the clove differently discussing medicinal aspects of clove and proving it as an alternative medicine affecting various body systems ${ }^{9-13}$. Above studies including our study suggest the clove possess medicinal properties. We could not include total, direct, indirect bilirubin and cellular pathologies on microscopic levels that remained the limitation of our study. On the bases of our current experiment we assume that in future clove extract may prove to be an alternative to $\mathrm{N}$-acetyl cysteine, a traditionally used drug for treating the Acetaminophin poisoning, if its active ingredient separated and studied both kinetically and dynamically. Clove has a great potential to be categorized as an allopathic drug by the interested pharmaceutical companies if further exploratory work possibly done.

\section{CONCLUSION}

Clove extract reversed the paracetamol induced liver toxicity in animal model.

\section{RECOMMENDATIONS}

1. More studies are recommended to explore the underlying mechanism by which clove and its components exert hepatic protective effects.

2. Comparative studies of clove extract with $\mathrm{N}$-acetyl cysteine are recommended to measure a difference of efficacy between the two agents.

\section{ACKNOWLEDGEMENTS}

We are thankful to Isra University for ethical and financial support. We are also thankful to Mr. Abdul Rauf Samoo and Nisar Ahmed for their assistance in typing this article and animal handling respectively.

\section{DECLARATION OF CONFLICT}

No conflict of interest.

\section{REFERENCES}

1. Diego Francisco Cortes-Rojas, Claudia Regina Fernandes de Souza, Wanderley Pereira Oliveira. Clove (Syzygium aromaticum): a precious spice, Asian Pac J Trop Biomed 2014; 4(2):90-96.

2. Kamatou GP, Vermaak I, Viljoen AM. Eugenol--From the Remote Maluku Islands to the International Market Place: A Review of a Remarkable and Versatile Molecule. Molecules 2012; 17(6): 6953-81.

3. Dalai Manoj K, Bhadra S, Chaudhary SK, Bandyopadhyay A, Mukharji PK. Anticholinesterase activity of the standardized extract of Syzygium aromaticum L. Pharmacogn Mag. 2014 Apr-Jun; 10(Suppl 2): S276-S282.

4. Rana IS, Rana AS, Rajak RC. Evaluation of antifungal activity in essential oil of the Syzygium aromaticum (L.) by extraction, purification and analysis of its main component eugenol. Braz J Microbiol. 2011 Oct-Dec; 42(4): 1269-1277.

5. Correia MA, Drug Biotransformation. In: Basic and Clinical Pharmacology, Bertram G. Katzung, Susan B. Masters, and Anthony J. Trevor. McGraw Hill Companies; 2012:53-68.

6. Karthivashan et al. The modulatory effect of Moringa oleifera leaf extract on endogenous antioxidant systems and inflammatory markers in an acetaminophen-induced nephrotoxic mice model, PeerJ 2016; 4:e2127.

7. Kazi S, Abbasi P, Arain AA. Syzygium aromaticum: a potential hepatoprotective agent, JSZMC 2016; 7(2):956-959.

8. Abdel-Rahman MK, El-Megeid AAA. Hepatoprotective Effect of Soapworts (Saponaria officinalis),Pomegranate Peel (Punica granatum $\mathrm{L}$ ) and Cloves (Syzygium aromaticum linn) on Mice with $\mathrm{CCl}$ Hepatic Intoxication, World J Chem 2006; 1(1):41-46.

9. Taher YA, Samud AM, El-Tahir F, ben-Hussin G, Elmezogi JS, Al-Mehdawi BF, et al. Experimental evaluation of anti-inflammatory, antinociceptive and antipyretic activities of clove oil in mice. Libyan J Med. 2015; 10: 10.28685.

10. Daniel J Davis, Jenna Klug, Miriam Hankins, Holly M Doerr, Stephanie R Monticelli, Ava Song, et al. Effects of Clove Oil as a Euthanasia Agent on Blood Collection Efficiency and Serum Cortisol Levels in Danio rerio. J Am Assoc Lab Anim Sci. 2015; 54(5):564-7. 
11. Jin-Yang Shen, Xiao-Lin Yang, Zhong-Lin Yang, Jun-Ping Kou, Fei Li. Enhancement of absorption and bioavailability of echinacoside by verapamil or clove oil. Drug Des Devel Ther. 2015; 9:4685-93.

12. Gihan S Labib, Hibah Aldawsari. Innovation of natural essential oil-loaded Orabase for local treatment of oral candidiasis. Drug Des Devel Ther. 2015; 9: 3349-59.

13. Nunez L, Aquino MD. Microbicide activity of clove essential oil (Eugenia caryophyllata). Braz J Microbiol. 2012; 43(4):1255-60.

AUTHOR AFFILIATION:

Dr. Sadia Kazi (Corresponding Author)

Assistant Professor, Department of Pharmacology Isra University Hyderabad, Sindh-Pakistan.

Email: sadia_kazi@hotmail.com

Dr. Mashkoor Ahmed Ansari

Assistant Professor, Department of Pharmacology

Bhattai Dental College Mirpukhas, Sindh-Pakistan.

Dr. Ashfaque Rahim Memon

Associate Professor, Department of Pharmacology

Al-Nafees Medical University Islamabad, Pakistan.

Dr. Abdul Rahim Memon

Professor, Department of Pharmacology

Isra University Hyderabad, Sindh-Pakistan.

Dr. Ashique Ali Arain

Assistant Professor, Department of Pharmacology

Isra University Hyderabad, Sindh-Pakistan.

Dr. Qamar Zaman Phull

Assistant Professor, Department of Pharmacology

Bilawal Medical College

LUMHS, Jamshoro, Sindh-Pakistan. 